\title{
Timing of first feeding and life-history strategies in salmon: genetic data
}

\author{
H. PINEDA ${ }^{1}$, Y.J. BORRELL ${ }^{1,2}$, I. MCCARTHY ${ }^{3}$, E. VÁZQUEZ ${ }^{1}$, J.A. SÁNCHEZ ${ }^{1}$ and G. BLANCO ${ }^{1}$ \\ ${ }^{1}$ Departamento de Biología Funcional, Universidad de Oviedo, Oviedo, Asturias, Spain \\ ${ }^{2}$ Departamento de Bioquímica, Universidad de la Habana, Vedado, Plaza, Cuba \\ ${ }^{3}$ School of Ocean Sciences, University of Wales-Bangor, Anglesey, UK
}

\begin{abstract}
Pineda, H., Borrell, Y. J., McCarthy, I., Vázquez, E., Sánchez, J. A. and Blanco, G. 2003. Timing of first feeding and life-history strategies in salmon: genetic data.-Hereditas 139: 41-48. Lund, Sweden. ISSN 0018-0661. Received September 24, 2001. Accepted August 26, 2003

To investigate the relationship between genetic composition and some physiological traits of interest (age at smoltification, precocious maturation in male parr) in early and late first feeding Atlantic salmon, genetic variation at 6 isozyme and 8 microsatellite loci was examined. Early and late first feeding salmon showed different allelic and genotypic distributions at both isozyme and microsatellite loci. A positive relation between enzymatic loci heterozygosity and precocious active alimentation and earlier smoltification (S1 cf. S2) were also found.
\end{abstract}

Gloria Blanco, Departamento de Biología Funcional, Area de Genética, Universidad de Oviedo, ES-33071 Oviedo, Asturias, Spain. E-mail: gbl@correo.uniovi.es

The change in the size-frequency distribution from normal to bimodal over time is a well-known phenomenon in both natural (HEGGenes and METCALFE 1991; NicIEZA et al. 1991) and cultivated (MetCAlfe et al. 1989; BlanCo et al. 1998) populations of Atlantic salmon. It is important due to the influence of bimodality in the subsequent smolting rates and in the timing of seaward migration (BAILEY et al. 1980; BAILEY and FriARs 1994). Smolting rate is a trait of particular interest for both cultured and in wild populations and much of the interest has been focussed on studying the behaviour and growth of the morphotypes in the upper and lower modal groups in the bimodal size-frequency distribution (THORPE et al. 1992). Although the factors that control life-history variation in Atlantic salmon are not fully understood, different studies indicate that the physiological state, the size and the growth rate of an individual will determine whether the animal adopts the early maturing or early migrant strategy the following year (THORPE et al. 1998). Some studies have suggested a threshold size beyond smolting can occur in a given populations (reviewed by THORPE et al. 1992). The developmental rate in the alevin phase and in the relative timing of first feeding can, on the other hand, influence the social status and the subsequent life-history strategy (METCALFE and THORPE 1992). Temporal variation of up to two weeks has been reported in the timing of first feeding within groups of Atlantic salmon in wild populations (GusTAVSON-MARJANEN and Dowse 1983; Beall et al. 1994) and in cultivated groups (MetCALFE and THORPE 1992; BRANNAS 1995). It has been reported that fish that has completed their alevin phase more quickly and were earlier to active first-feed, tended to be dominant over their later feeding siblings, grew faster and were more likely to smolt at an earlier age (MetCAlfe and Thorpe 1992).

Previous work on salmonid fish has shown a family effect on developmental rate during the alevin phase (BEACHAM et al. 1985; DE MARCH 1995) and on growth rate in freshwater (THORPE and MORGAN 1978). There are also evidence of isozyme pattern differences between fish adopting different life-history strategies (CARL and HeAley 1984; SÁNCHEZ et al. 1994, BlanCO et al. 1998, Presa et al. 1996).

However, Atlantic salmon populations usually show lower levels of genetic variation at protein-coding loci and, in general, six loci $\left(M D H-3,4^{*}, m M E P\right.$ $2^{*}, I D H P-3^{*}, S A A T-4^{*}, I D D H-1^{*}$ and IDDH-2*) account for more than $95 \%$ of the total gene diversity in the species (CROSS and WARD 1980; STAHL 1987; DAVIDSON et al. 1989; BourKe et al. 1997). Allozymes have therefore a limited value as genetic markers and thus alternative methods are required in order to make more detailed analyses of genetic variation in this species. Currently, new molecular genetic markers, like RFLPs, AFLPs, RAPDs, minisatellite, microsatellite, etc., are being developed and between them, microsatellite markers exhibit attributes that make them particularly suitable for genetic characterisation; for example, they are very abundant, exhibit usually high levels of allelic variation, are codominant markers inherited in a Mendelian fashion and, in addition, only small amounts of tissue are required for analysis (WRIGHT and BENTZEN 1995; JARNE and LAGODA 1996). 
In this work, a characterization of genetic diversity of different groups into timing of first active feeding and life-history strategies in Atlantic salmon was carried out using 6 allozymes and 8 microsatellites markers.

\section{MATERIAL AND METHODS}

\section{Fish and husbandry}

A 400 family cross of eggs ( 20 males $\times 20$ females) were obtained from multi-sea winter adult Atlantic salmon returning to spawn in the River Shin (Kyles of Sutherland, Scotland). The fertilized eggs were reared at the Scottish Office Environment Agriculture and Fisheries Department (SOEAFD) Smolt Rearing Unit at Almondbank, Perthshire, until the eggs were eyed when approximately 1000 eggs were randomly sampled, transported to laboratory and reared in egg incubators. The fish were examined daily to check the rate of yolksac absorption and any dead individuals removed. The mortality rate in the alevin phase was $12 \%$ (121 fishes). On 25 May 1994, the fish were divided by eye into three groups, early $(n=243)$, intermediate $(\mathrm{n}=543)$ and late $(\mathrm{n}=160)$ first feeding fish according to the amount of yolk remaining using the classification of METCALFE and THORPE (1992). On 25 May 1994, 150 early first feeding fish (EF), who had almost exhausted their yolk reserves, were randomly selected, placed into a $1 \mathrm{~m}$ diameter circular tank supplied with aerated freshwater and offered food (hatch to first feed $=290$ degree days). The late first feeding fish (LF) were placed in a separate tank and reared until they were assessed as ready to be offered food on 4 June 1994 (hatch to first feed $=395$ degree days) when 150 late first feeding fish were randomly selected, anaesthetised (MS 222, $0.1 \mathrm{~g}^{-1}$ ), their anal fin carefully removed and added to the tank containing the early first feeding fish. No mortalities occurred as a result of the tagging process.

The fish were reared together in freshwater from 4 June 1994 until 19 April 1995 (320 days). The fish were fed to excess on a commercial fish food diet (BP Nutrition UK Ltd) daily during daylight hours using a clockwork belt feeder. The diet pellet size was changed in accordance with the manufacturers recommendations as the fish increased in size. Towards the end of the experiment, as the range of fish size within the group increased, a mixture of pellet sizes were offered to the group to ensure that food of an appropriate size was available to all the fish in the tank. The fish exposed to the natural variation in photoperiod for the duration of the experiment and experienced ambient water temperatures from May to November 1994 (May $14 \pm 0.9^{\circ} \mathrm{C}$; August 17.4 \pm $0.5^{\circ} \mathrm{C}$; November $11.5 \pm 0.8^{\circ} \mathrm{C}$ ). However, over the winter the water supply was heated and the water temperature remained above $10.5^{\circ} \mathrm{C}$ for the rest of the experiment. On 19 April 1995, the fish were killed, identified as S1 smolts or S2 parr and sexed as immature male, mature precocious male or immature female fish. The liver and a white muscle sample were taken from the fish and rapidly frozen, together with the whole carcass by immersion in liquid nitrogen. All dissections were completed within 2 minutes of death and the samples stored at $-70^{\circ} \mathrm{C}$ until they were shipped on dry ice to Oviedo (Asturias, Spain) where they were stored at $-70^{\circ} \mathrm{C}$ until genetic analysis.

\section{Protein analysis}

Tissue samples of liver and muscle were analyzed by horizontal starch gel electrophoresis. Six polymorphic loci were scored, $M D H-3,4^{*}, m M E P-2^{*}, I D H P$ $3^{*}, S A A T-4^{*}, I D D H-1^{*}$ and $I D D H-2^{*}$, using the procedures outlined in BLANCO et al. (1990) and SÁNCHEZ et al. (1991).

\section{Microsatellite analysis}

Genomic DNA was purified from skeletal muscle tissue using Chelex 100 Resin (BIO-RAD). Eight microsatellite loci were analyzed by specific PCR: SsaF43, SsaD30, Ssa2019 and Ssa13-37 (SÁNCHEZ et al. 1996), SSOSL311 and SSOSL417 (SLETTAN et al. 1995) and Str 543 and Str 15 (PRESA and GuYOMARD 1996).

Aliquots of amplification products were resolved on $6 \%$ denaturing polyacrylamide sequencing gels. The products were visualized by silver staining (Promega Silver sequence ${ }^{\mathrm{TM}}$ DNA Staining)

\section{Statistical analysis}

Allelic frequencies were estimated by direct counts. Test for deviations from Hardy-Weinberg proportions were carried out using either the exact test (Louis and Dempster 1987) or, when more than four alleles per locus were considered using the Markov chain method (GuO and THOMPSON 1992). Levels of genetic variation were based on observed heterozygosity, expected unbiased heterozygosity, percentage of polymorphic loci $\left(\mathrm{P}_{0.95}\right)$ and mean number of alleles per locus. Genic $\left[p\left(G_{\text {alleles }}\right)\right]$ and genotypic $\left[p\left(G_{\text {genot. }}\right)\right]$ differentiation were assessed using an unbiased estimate of the P-value of a log-likelihood (G) based exact test (GoudeT et al. 1996). Statistical differences in mean observed heterozygosity between groups were assessed using a student-t test. Other statistical analysis were performed using the BIOSYS-1 computer package (SWOFFORD and SELANDER 1989), GENEPOP (RAYMOND and Rous- 
SET 1995) and StatView SE + Graphic TM program (Macintosh HD).

\section{RESULTS}

The mortality rate during the experiment was $14 \%$. On 19 April 1995, the experimental population consisted of 161 smolts (S1) (2\%), 59 immature parr (S2) $(23 \%)$ and 38 precocious male parr (PMM) (15\%). The proportion of smolts, immature parr and precocious male parr was significantly different between the early (EF) and late (LF) first feeding groups $\left(\chi^{2}=35.39 ; \mathrm{p}<0.001\right)$. The EF fish consisted of 105 S1 (74.5\%), $12 \mathrm{~S} 2(8.5 \%)$ and 24 PMM (17\%) whereas the LF fish consisted of $56 \mathrm{~S} 1$ (48.0\%), $47 \mathrm{~S} 2$ (40.0\%) and 14 PMM (12\%).

\section{Sex groups analysis}

In order to investigate the effect of sex on genetic variability, the surviving salmon were divided into female $(\mathrm{n}=136)$ and male $(\mathrm{n}=112)$. It was not possible to sex 10 small parr and these fish were omitted from this analysis. Ten exclusive alleles in females (one at isozyme and nine at microsatellite loci) and one in males (at microsatellite SSO311* loci) were found (Table 1). However the total frequencies of them was 0.098 for females and 0.009 for males alleles indicating lower inter-sex differences.

From the isozymes loci examined, no significant differences were found between groups. Although one locus $\left(I D D H-2^{*}\right)$ reported significant differences between sex due to absence of IDDH-2*28 allele in males group (Table 1). Although 10 microsatellite alleles were found exclusively in either female or male fish, neither microsatellite loci reflected differences between females and males groups except for SSOSL311 locus, in which significant differences between sexes were found for allelic frequencies $(\mathrm{p}=$ $0.048)$ but not for genotypic distribution $(p=0.267)$. Therefore, based on these data, males and females were pooled for the following analysis.

\section{Timing at first feeding}

Allelic frequency and level of heterozygosity for the six enzymatic and eight microsatellite loci examined in the EF and LF salmon are shown in Table 2 and 3. For isozymes loci, significant differences were observed between EF and LF groups $(p=0.015)$ due to differences in allelic frequencies at $M E P-2^{*}$ locus (Table 2). EF fish also exhibited a significant $(\mathrm{p}=$ $0.020)$ higher mean heterozygosity $(\mathrm{Ho}=0.189)$ than LF $($ Ho $=0.145)$ (Table 2$)$. For microsatellites, significant differences $(\mathrm{p}<0.001)$ in allelic frequencies were also observed between EF and LF groups. These differences were mainly due to the SsaF43,
Table 1. Frequencies of sex-specific alleles at one allozyme and 4 microsatellite loci for a $20 \times 20$ family cross of Atlantic salmon from the River Shin (Kyles of Sutherland, Scotland).

\begin{tabular}{lll}
\hline Alleles & Females $(\mathrm{n}=136)$ & Males $(\mathrm{n}=112)$ \\
\hline IDDH-2-28 & 0.023 & 0.000 \\
SsaF43-109 & 0.007 & 0.000 \\
Ssa2019-84 & 0.004 & 0.000 \\
SSOSL417-177 & 0.004 & 0.000 \\
SSOSL417-199 & 0.012 & 0.000 \\
SSOSL417-209 & 0.004 & 0.000 \\
SSOS311-136 & 0.004 & 0.000 \\
SSOS311-158 & 0.012 & 0.000 \\
SSOS311-170 & 0.012 & 0.000 \\
SSOS311-174 & 0.016 & 0.000 \\
SSOS311-160 & 0.000 & 0.009 \\
\hline
\end{tabular}

n: sample size.

Table 2. Allelic frequencies for the 6 allozyme loci examined in early $(E F n=141)$ and late $(L F n=116)$ first feeding Atlantic salmon from River Shin (Kyles of Sutherland. Scotland).

\begin{tabular}{lcc}
\hline LOCUS/allele & EF & \multicolumn{1}{l}{ LF } \\
\hline$M D H-3.4$ & 0.029 & 0.004 \\
87 & 0.964 & 0.982 \\
100 & 0.007 & 0.013 \\
104 & & \\
$m M E P-2$ & 0.296 & 0.190 \\
100 & 0.704 & 0.810 \\
125 & & \\
$I D H P-3$ & 0.982 & 0.996 \\
100 & 0.018 & 0.004 \\
115 & & \\
$s A A T-4$ & 0.182 & 0.208 \\
50 & 0.818 & 0.792 \\
100 & & \\
$I D D H-1$ & 0.289 & 0.226 \\
72 & 0.711 & 0.774 \\
100 & & \\
$I D D H-2$ & 0.018 & 0.009 \\
28 & 0.982 & 0.991 \\
100 & 0.189 & 0.145 \\
$\mathrm{Ho}$ & 0.212 & 0.175 \\
$\mathrm{He}$ & 50 & 50 \\
$\mathrm{P}$ & 2.95 & 2.17 \\
\hline & &
\end{tabular}

n: sample size; Ho: Mean observed heterozygosity; He: Mean expected heterozygosity; $\mathrm{P}_{0.95}$ : proportion of polymorphic loci (0.95); Na: Mean number of alleles per locus..

Ssa2019, SSOSL311 and SSOSL417 loci $(\mathrm{p}<0.05$ in all cases, Table 3). However, no significant differences were observed in heterozygosity between EF and LF classes at microsatellites loci (Table 3). Nine 
Table 3. Allelic frequencies for the 8 microsatellite loci examined in early $(E F n=141)$ and late $(L F n=116)$ first feeding Atlantic salmon from River Shin (Kyles of Sutherland. Scotland). Boldface denotes specific alleles.

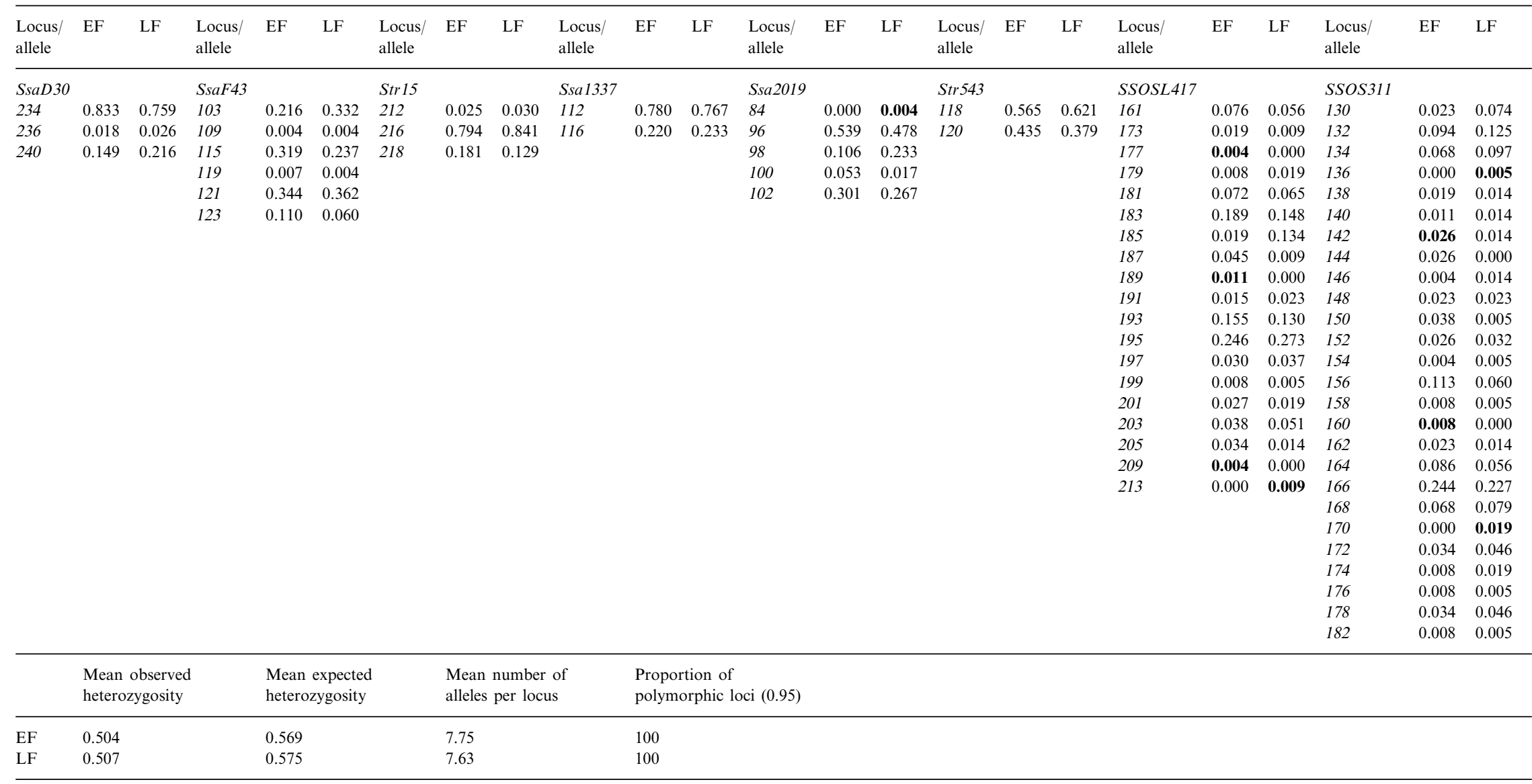


Table 4. Genetics comparison among physiological groups inside early (EF) and late (LF) first feeding fish group of Salmo salar L. from River Shin (Scotland): Smolt (S1), parr (S2) and precocious mature males fish (PMM).

\begin{tabular}{llllllll}
\hline & \multicolumn{3}{c}{ Isozymes } & & \multicolumn{3}{c}{ Microsatellites } \\
\cline { 2 - 3 } \cline { 6 - 7 } & $\mathrm{S} 1$ & $\mathrm{~S} 2$ & PMM & & S1 & S2 & PMM \\
\hline a) $\mathrm{EF}$ & & & & & & \\
$\mathrm{n}$ & 105 & 12 & 24 & & 105 & 12 & 24 \\
$\mathrm{Ho}$ & 0.194 & 0.136 & 0.194 & & 0.495 & 0.528 & 0.532 \\
$\mathrm{He}$ & 0.212 & 0.223 & 0.210 & & 0.567 & 0.561 & 0.572 \\
$\mathrm{P}_{0.95}$ & 50 & 66.67 & 50 & & 100 & 100 & 100 \\
$\mathrm{Na}$ & 2.17 & 1.67 & 2.00 & & 7.75 & 4.50 & 5.25 \\
$\mathrm{~b}) \mathrm{LF}$ & & & & & & \\
$\mathrm{N}$ & 56 & 46 & 14 & & 56 & 46 & 14 \\
$\mathrm{Ho}$ & 0.155 & 0.117 & 0.190 & & 0.464 & 0.546 & 0.549 \\
$\mathrm{He}$ & 0.174 & 0.166 & 0.211 & & 0.563 & 0.585 & 0.594 \\
$\mathrm{P}$ & 50 & 50 & 50 & & 100 & 100 & 100 \\
$\mathrm{Na}$ & 2.00 & 2.00 & 2.00 & & 6.75 & 6.38 & 4.50 \\
\hline
\end{tabular}

$\mathrm{n}$ : sample size; Ho: mean observed heterozygosity; He: mean expected heterozygosity; $\mathrm{P}_{0.95}$ : proportion of polymorphic loci (0.95); Na: mean number of alleles per locus.

exclusive alleles in either EF or LF groups could be identified from microsatellites loci, however their low frequencies (0.004-0.019) indicates that they are not suitables for use as specific markers of one or another group (Table 3).

\section{Comparison between morphotypes}

No significant differences were found in the allelic or genotypic distributions for the 6 isozymes loci examined between morphotypes (S1 smolt, S2 parr, precocious mature male (PMM) parr) within either the EF or LF groups. However, in both groups, S2 parr exhibited lower enzymatic heterozygosity than S1 smolts and the PMM, whereas there were not differences in heterozygosity between the S1 and PMM (Table 4). At microsatellite loci, S1 smolts exhibited, in both groups, a lower observed mean heterozygos- ity than presented by S2 parr and PMM group (Table $4)$. The only significant difference was recorded between $\mathrm{S} 1$ and S2 parr in LF group $(\mathrm{p}=0.0063)$. There were no significant differences in relation to heterozygosity between S2 parr and PMM in either EL or FL groups (Table 4).

Six specific alleles could be identified for S1 smolt, but they are not useful as physiological marker because extremely low frequencies were found for all those exclusive alleles in any groups (Table 5).

\section{DISCUSSION}

In the present study, none of the six protein-coding or eight microsatellite loci examined provided, on an individual basis, any useful association with either the relative timing at first feeding (early vs late) or with life history strategy (early vs delayed migrant, precocious freshwater maturation in male parr). The microsatellite loci revealed the presence of alleles found exclusively in male or female fish $(\mathrm{n}=10$; Table 1$)$, in early or late first feeding salmon $(n=9$; Table 3$)$ or in fish adopting the early migrant strategy (S1 smolts; $\mathrm{n}=6$; Table 5). However, these alleles were present at very low frequencies and are therefore not suitable to be used as sex- or 'state'-specific markers. In contrast, the isozyme loci revealed differences in the pattern of overall genetic variability between the different groups of fish. LF fish exhibited significantly lower levels of variability than the EF feeding fish (Table 2). Also, within both the early and late first feeding fish, S2 parr fish exhibited a significantly lower mean heterozygosity compared to PMM parr and S1 smolts, with the latter two morphotypes exhibiting similar levels of mean heterozygosity (Table 4). These differences in mean heterozygosity may help to explain why the EF salmon tended to adopt alternative life history strategies compared to EF feeding fish. BLANCO et al. (1998), in an experiment with individually tagged Atlantic salmon, found, at the end of a year-long experiment, that the more heterozygous

Table 5. Frequencies of physiological exclusive microsatellite alleles in early (EF) and late (LF) first feeding fish groups of Salmo salar L. from River Shin (Scotland). Smolt (S1), parr (S2) and precocious mature males fish $(P M M)$.

\begin{tabular}{|c|c|c|c|c|c|c|}
\hline \multirow[b]{2}{*}{ Alleles } & \multicolumn{3}{|c|}{$\mathrm{EF}$} & \multicolumn{3}{|c|}{ LF } \\
\hline & S1 & S2 & PMM & $\mathrm{S} 1$ & S2 & PMM \\
\hline SSOSL417-191 & 0.020 & 0.000 & 0.000 & 0.050 & 0.000 & 0.000 \\
\hline SSOSL417-199 & 0.010 & 0.000 & 0.000 & 0.010 & 0.000 & 0.000 \\
\hline SSOS311-140 & 0.015 & 0.000 & 0.000 & 0.029 & 0.000 & 0.000 \\
\hline SSOS311-154 & 0.005 & 0.000 & 0.000 & 0.010 & 0.000 & 0.000 \\
\hline SSOS311-158 & 0.010 & 0.000 & 0.000 & 0.010 & 0.000 & 0.000 \\
\hline SSOS311-176 & 0.010 & 0.000 & 0.000 & 0.010 & 0.000 & 0.000 \\
\hline
\end{tabular}


individuals were larger, heavier and had higher growth rates compared to their homozygous sibling.

In the present study, if the EF and LF fish are compared as a whole, the EF salmon exhibited higher levels of enzymatic heterozygosity than the LF feeding fish (Table 2). However, when the EF and LF feeding salmon are divided up into the three morphotype classes (S1, PMM and S2), it is interesting to note that the levels of mean enzymatic heterozygosity were similar in the EF and LF fish adopting each of the three life history strategies (Table 4). The only difference was that the proportions of fish in each of the three morphotype classes were significantly different between the EF and LF groups: the EF group comprising of $74.5 \%$ S1 smolts, $17 \%$ precocious mature male parr and $8.5 \% \mathrm{~S} 2$ parr respectively, while in contrast the LF group comprising of $48 \% \mathrm{~S} 1$ smolts, $12 \%$ precocious mature male parr and $40 \%$ S2 parr respectively (Table 4).

In both groups PMM (males that matured at the end of their first year of life) fish can be observed. These fish did not show significant differences in enzymatic heterozygosity when comparison were made with $\mathrm{S} 1$ smolts into each classes (EF or LF). However PMM fish are intermediate in length (data not shown). These differences among individuals with similar levels of heterozygosity are due to the different life history strategies adopted by each group (PMM or S1). PMM fish initiate maturation in late summer and deviate more energy to gonad development and gamete production than to somatic tissue elaboration. During this time PMM fish grow less than S1 smolts, but after this time (at the end of winter) PMM fish show similar growth rates than S1 smolts (BLANCO et al. 1998). Some of PMM fish (in this study $80 \%$ of PMM-EF and $78.57 \%$ of PMMLF) can reach the minimum threshold size and subsequently undergo smoltification in next spring.

The results of this study show a clear relationship between levels of enzymatic heterozygosity, timing of first feeding and morphotype in juvenile Atlantic salmon. Thus, the most heterozygous individuals tend to complete the alevin phase more quickly, begin first feeding earlier, grow faster and attain the threshold size for smoltification (THORPE et al. 1998) after $1 \mathrm{yr}$ in freshwater (S1 smolts) compared to the less heterozygous salmon. This positive correlation between isozyme heterozygosity and morphological variation and fitness components has been reported in a wide variety of animal and plant species (MITTON and GrANT 1984, Zouros and FOLT 1987; LISKAUSKAS and Ferguson 1990, 1991, Zouros and Pogson 1994, MitTon 1997, 1998). In Atlantic salmon, the association between genetic variability and size (length, weight) and morphotype is now well estab- lished (JORDAN et al. 1990; JORDAN and YOUNGSON 1991; Torrisen 1991; Pollard et al. 1994; SÁNCHEZ et al. 1994; BlANCO et al. 1998; this study). It is thought that the association with enzyme heterozygosity may be through the control of metabolic reactions, with increased levels of heterozygosity enhancing physiological efficiency by decreasing the energetic cost of standard metabolism (MitTon and KoEHN 1985; KoEHN et al. 1988).

In spite of their potential to yield greater levels of genetic variability, the eight microsatellite loci examined in this study did not allow us to identify specific allele markers for any of the parameters of interest (sex, timing of first feeding or morphotype). However, the microsatellite loci did highlight, with greater clarity than the isozyme analyses, the differences in genetic constitution that were present in this study (Table 1, 3 and 5). The levels of heterozygosity that are recorded using microsatellites loci do not follow the same patterns as those observed using isozymes. For example the early migrant fish (S1 smolts) in both ( EF and LF) groups showed lower levels of heterozygosity using microsatellite analysis compared to the delayed migrants (S2 parr) which was the opposite result to that found using isozymes (Table 4). These results could be interpreted as suggesting that a negative correlation exists between size and heterozygosity when assessed using microsatellite loci; in other words, individuals with lower levels of microsatellite heterozygosity grow faster than more heterozygous individuals. However, this is unlikely since microsatellites are considered to be selectively neutral markers, although, certainly, there have been carried out few studies comparing heterozygosity at DNA markers with fitness-related traits and the results obtained have not shown any consistent pattern. So, POGSON and Zouros (1994) reported a significant positive correlation between growth rate and heterozygosity at seven isozyme loci in a cohort of juveniles scallops (Placopecten magellanicus) but did not find the same correlation using RFLP's markers. Pogson and Fevolden (1998) also reported a positive association between the degree of individual DNA heterozygosity (assessed ten nuclear RFLP's) growth rate and body length in one population (Bolsjord) of Atlantic cod (Gadus morhua) but not in other (Barents Sea population). No association has been reported between microsatellite heterozygosity and either birth weight in harbour seal pups (COLTMAN et al. 1998) or neonatal survival in red deer (Coulson et al. 1998). Zouros and Pogson (1994) examined the effects of heterozygosity (assessed using 7 isozymes, 2 protein, 2 RFLP's and 5 VNTR's) on shell length in a scallop and reported a positive correlation between shell length and enzymatic het- 
erozygosity, but negative correlations using the rest of markers. Clearly, further research is needed to clarify the relationship between variability at microsatellite loci and fitness in Atlantic salmon and to further examine the functionality of microsatellite loci.

Acknowledgements - We thank Charlie Menzies and staff (Kyle of Sutherland District Fishery Board) for provision of fish eggs and Mike Miles and staff (SOAEFD smolt rearing unit, Almondbank) for initially rearing the alevins. We also thank Leyton Hackney, Dr. Stewart Owen and Dr. Patrick Campbell for their help with fish husbandry and tissue sampling. This research was carried out under licence from the UK Home Office and was funded with grants from EU (96-036), the Spanish government (MEC-UE980017), the AECI and the BBSRC (PG1/588 GER).

\section{REFERENCES}

Bailey, J. K. and Friars, G. W. 1994. Sources of variation in age at smolting in hatchery-reared Atlantic salmon (Salmo salar). - Can. J. Anim. Sci. 74: 223-227.

Bailey, J. K., Saunders, R. L. and Buzeta, M. I. 1980. Influence of parental smolt age and sea age on growth and smolting of hatchery-reared Atlantic salmon (Salmo salar). - Can. J. Fish. Aquat. Sci. 37: 1379-1386.

Beacham, T. D., Withler, F. C. and Morley, R. B. 1985. Effect of egg size incubation time and fry size in chum salmon and coho salmon. - Can. J. Zool. 63: 847-850.

Beall, E., Dumas, J., Claireaux, D. et al. 1994. Dispersal patterns and survival of Atlantic salmon juveniles in a nursery stream. - ICES J. Mar. Sci. 51: 1-9.

Blanco, G., Sánchez, J. A., Vazquez, E. et al. 1990. Superior developmental stability of heterozygotes at enzyme loci in Salmo salar L. - Aquaculture 84: 199-209.

Blanco, G., Presa, P., Vazquez, E. et al. 1998. Allozyme heterozygosity and development in Atlantic salmon. Fish Physiol. Biochem. 19: 163-169.

Bourke, E. A., Coughlan, J., Jansson, H. et al. 1997. Allozyme variation in populations of Atlantic salmon located throughout Europe: diversity that could compromised by introduction of reared fish. - ICES J. Mar. Sci. 54: 974-985.

Brannas, E. 1995. First access to territorial space and exposure to strong predation pressure: a conflict in early emerging Atlantic salmon fry. - Evol. Ecol. 9: 411-420.

Carl, L. M. and Healey, M. C. 1984. Differences in enzyme frequency and body morphology among three juvenile life history types of chinook salmon in the Nanaimo River. - Can. J. Fish. Aquat. Sci. 41: 1070-1077.

Coltman, D. W., Bowen, W. D. and Wright, J. M. 1998. Birth weight and neonatal survival of harbour sea pups are positively correlated with genetic variation measured by microsatellites. - Proc. R. Soc. Lond. B265: 803809.

Coulson, T. N., Pemberton, J. M. and Albon, S. D. 1998. Microsatellites reveal heterosis in red deer. - Proc. R. Soc. Lond. B265: 489-495.

Cross, T. F. and Ward, R. D. 1980. Protein variation and duplicate loci in the Atlantic salmon, Salmo salar L. Genet. Res. 36: 147-165.
Davidson, W. S., Birt, T. P. and Green, J. M. 1989. A review of genetic variation in Atlantic salmon, Salmo salar L. and its importance for stock identification, enhancement programmes and aquaculture. - J. Fish Biol. 34: 547-560.

de March, B. G. E. 1995. Effects of temperature on the hatching success of Arctic char eggs. - The Progressive Fish Culturist 57: 132-136.

Goudet, J., Raymond, M., De Meeus, T. et al. 1996. Testing differentiation in diploid populations. - Genetics 144: 933-1940.

Guo, S. W. and Thompson, E. A. 1992. Performing the exact test of Hardy-Weinberg proportions for multiple alleles. - Biometrics 48: 361-372.

Gustavson-Marjanen, K. I. and Dowse, H. B. 1983. Seasonal and diel patterns of emergence from the redd by Atlantic salmon fry. - Can. J. Fish. Aquat. Sci. 40: 813-817.

Heggenes, J. and Metcalfe, N. B. 1991. Bimodal size distributions in wild juvenile Atlantic salmon populations and their relationship with age at smolt migration. - J. Fish Biol. 39: 905-907.

Jarne, P. and Lagoda, J. L. 1996. Microsatellites, from molecules to populations and back. - Trends Ecol. Evol. 11: 424-429.

Jordan, W. C. and Youngson, A. F. 1991. Genetic protein variation and natural selection in Atlantic salmon parr. - J. Fish Biol. 39: 185-192.

Jordan, W. C., Youngson, A. F. and Webb, J. H. 1990. Genetic variation at the malic enzyme-2 locus and age at maturity in sea-run Atlantic salmon. - Can. J. Fish. Aquat. Sci. 47: 1672-1677.

Koehn, R. K., Diehl, W. and Scott, T. M. 1988. The differential contribution by individual enzymes of glycolysis and protein catabolism to the relationship between heterozygosity and growth rate in the coot clam Mulinia lateralis. - Genetics 118: 121-130.

Liskauskas, A. P. and Ferguson, M. M. 1990. Enzyme heterozygosity and fecundity in naturalized populations of brook trout. - Can. J. Fish. Aquat. Sci. 47: 20102015.

Liskauskas, A. P. and Ferguson, M. M. 1991. Genetic variation and fitness: a test in a naturalized population of brook trout. - Can. J. Fish. Aquat. Sci. 48: 21522162.

Louis, E. J. and Dempster, E. R. 1987. An exact test for Hardy-Weinberg and multiple alleles. - Biometrics 43: 805-811.

Metcalfe, N. B. and Thorpe, J. E. 1992. Early predictors of life-history events: the link between first feeding date, dominance and seaward migration in Atlantic salmon. J. Fish Biol. 41: 93-99.

Metcalfe, N. B., Huntingford, F. A., Graham, W. D. et al. 1989. Early social status and development of life-history strategies in Atlantic salmon. - Proc. R. Soc. Lond. B236: 7-19.

Mitton, J. B. 1997. Selection in natural populations. Oxford Univ. Press.

Mitton, J. B. 1998. Molecular markers and natural selection. Advances in molecular ecology. - In: Carvalho, G. R. (ed.), IOS Press, Netherlands, pp. 225-241.

Mitton, J. B. and Grant, M. C. 1984. Association among protein heterozygosity, growth rate and developmental homeostasis. - Annu. Rev. Ecol. Syst. 15: 479-499. 
Mitton, J. B. and Koehn, R. K. 1985. Shell shape variation in the blue mussel and its association with enzyme heterozygosity. - J. Exp. Mar. Biol. Ecol. 90: 73-80.

Nicieza, A. G., Braña, F. and Toledo, M. M. 1991. Development of length-bimodality and smolting in wild stocks of Atlantic salmon, Salmo salar, under different growth conditions. - J. Fish Biol. 38: 509-523.

Pogson, G. H. and Zouros, E. 1994. Allozymes and RFLP's heterozygosities as correlates of growth rate in the scallop Placopecten magellanicus: a test of the associative overdominance hypothesis. - Genetics 137: 221231.

Pogson, G. H. and Fevolden, S. E. 1998. DNA heterozygosity and growth rate in the Atlantic cod Gadus morhua L. - Evolution 52: 915-920.

Pollard, S. M., Danzmann, R. G. and Claytor, R. R. 1994. Association between regulatory locus $P G M-1 r^{*}$ and lifehistory types of juvenile Atlantic salmon. - Can. J. Fish. Aquat. Sci. 51: 1322-1329.

Presa, P. and Guyomard, R. 1996. Conservation of microsatellites in three species of salmonids. - J. Fish Biol. 49: $1326-1329$.

Presa, P., Blanco, G., Vázquez, E. et al. 1996. Life-history transitions among Atlantic salmon (Salmo salar) morphotypes. - Can. J. Anim. Sci. 76: 35-40.

Raymond, M. and Rousset, F. 1995. GENEPOP: populations genetics software for exact tests and ecumenicism. - J. Heredity 86: 248-249.

Sánchez, J. A., Blanco, G., Vazquez, E. et al. 1991. Allozyme variation in natural populations of Atlantic salmon in Asturias (northern Spain). - Aquaculture 93: 291-298.

Sánchez, J. A., Vazquez, E. and Blanco, G. 1994. Relationships between genetic variability and precocious maturity and smolting in Atlantic salmon. - ICES C.M. M 27.

Sánchez, J. A., Clabby, C., Ramos, D. et al. 1996. Protein and microsatellite single locus variability in Salmo salar L. (Atlantic salmon). - Heredity 77: 423-432.
Slettan, A., Olsaker, I. and Lie, O. 1995. Atlantic salmon, Salmo salar L, microsatellites at the SSOSL311, SSOSL417, SSOSL85, SSOSL25 loci. - Anim. Genet. 26: $277-285$.

Stahl, G. 1987. Genetic population structure of Atlantic salmon. - In: Ryman, N. and Utter, F. (eds), Popul. Genet. Fish. Manage. Univ. of Washintong Press, pp. $121-140$.

Swofford, D. L. and Selander, B. 1989. BIOSYS-1. A computer program for the analysis of allelic variation in population genetics and biochemical systematics. Release 1.7. - Univ. of Illinois.

Torrisen, K. R. 1991. Genetic variation in growth rates with different trypsin-like isozymes patterns. - Aquaculture 93: 299-312.

Thorpe, J. E. and Morgan, R. 1978. Parental influence on growth rate, smolting rate and survival in hatchery reared juvenile Atlantic salmon, Salmo salar. - J. Fish Biol. 13: 549-556.

Thorpe, J. E., Metcalfe, N. B. and Huntingford, F. A. 1992. Behavioural influences on life-history variation in juvenile Atlantic salmon, Salmo salar. - Environ. Biol. Fish. 33: 331-340.

Thorpe, J. E., Mangle, M., Metcalfe, N. B. et al. 1998. Modelling the proximate basis of salmonid life-history variation, with application to Atlantic salmon Salmo salar L. - Evol. Ecol. 12: 581-599.

Wright, J. M. and Bentzen, P. 1995. Microsatellites: genetics markers for the future. - In: Carvalho, G. R. and Pitcher, T. J. (eds), Molecular genetics in Fisheries, pp. $116-121$.

Zouros, E. and Foltz, D. W. 1987. The use of allelic isozyme variation for the study of heterosis. - Isozymes: Curr. Topics Biol. Med. Res. 13: 1-59.

Zouros, E. and Pogson, G. H. 1994. Heterozygosity, heterosis and adaptation. - In: Beaumont, A. (ed.), Genetics and evolution of aquatic organisms. Chapman-Hall, pp. $135-146$. 